\title{
THE SOVIET SCHOOL SYSTEM IN CENTRAL INTELLIGENCE AGENCY ESTIMATES AT THE INITIAL STAGE OF THE COLD WAR
}

(C) 2020

Mamedov Zaur Imalverdi oglu, postgraduate student of World History, Law and Methods of Teaching Department Samara State University of Social Sciences and Education (Samara, Russian Federation)

Abstract. The paper is devoted to the analysis by the Central Intelligence Agency of the USSR school system. The US was in dire need of information about its new adversary. The situation was aggravated by the closed nature of the Soviet state and the absence of a long continuous tradition of intelligence activities of American intelligence. The president and other government bodies wanted to have comprehensive knowledge of any processes and phenomena in the world. US intelligence should have been able to solve this problem. In this regard, the first stage of the Cold War for the CIA was largely due to an analysis of official and semi-official sources, as well as the development of various strategies. In order to find out about various areas of the life in the USSR, analysts extracted information from Soviet scientific literature, press, radio, legislation and interrogations of former German prisoners. The National Assessment Bureau, led by William Langer and Sherman Kent, compiled reports on Soviet military capabilities, industry, agriculture, the political system, etc. The Soviet school system was considered by American intelligence specialists in the framework of the military and economic potential of the enemy, as well as the strategy of psychological warfare. The paper analyzes the reports concerning the educational system in the USSR in the aspect of school education, its strengths and weaknesses. The results allow us to conclude that the information about the Soviet school system contributed to the formation of the foreign policy and domestic policy of the United States.

Keywords: Central Intelligence Agency; USA; USSR; Cold War; American intelligence; school system; psychological warfare; Soviet Union; educational system; Stalin; Truman; Walter Bedell Smith; Sherman Kent; William Langer; Robert Byrnes; Bureau of National Assessments; education; military potential; educational policy.

\section{РАЗВИТИЕ МЕДИЦИНЫ КАК ФАКТОР «ЭПИДЕМИЧЕСКОГО ПЕРЕХОДА» У ГОРОДСКОГО НАСЕЛЕНИЯ СРЕДНЕГО ПОВОЛЖЬЯ}

(C) 2020

\author{
Румянцева Мария Александровна, кандидат исторических наук, доцент, \\ научный сотрудник кафедры «Экономика и менеджмент» \\ Филиал Самарского государственного технического университета в г. Новокуйбышевске \\ (2. Новокуйбышевск, Самарская область, Российская Федераџия)
}

\begin{abstract}
Аннотация. В представленной статье автор рассматривает развитие медицины в двадцатом веке как фактор, который существенным образом изменил заболеваемость, а с ней и смертность населения Среднего Поволжья. Появление пенициллина и стрептомицина, массовые прививочные кампании и пропаганда здорового труда и быта, борьба с переносчиками заболеваний и успехи медицинской науки, рост числа врачей и больничных коек на душу населения и доступная бесплатная медицинская помощь - все это привело к значительному уменьшению числа опасных эпидемий в стране. Не обошли данные процессы и городское население Среднего Поволжья. До единичных случаев снижается заболеваемость полиомиелитом и малярией, сибирской язвой и туляремией, чумой и дифтерией, натуральной оспой и холерой, в разы уменьшилась заболеваемость тифом и дизентерией, что привело к сдвигу в структуре смертности населения региона, экзогенные факторы смертности уступают место эндогенным. Смещение заболеваемости в сторону новообразований и сердечно-сосудистых заболеваний - это тоже тенденция времени. И именно произошедший во второй половине XX века процесс «эпидемического перехода» как части перехода демографического определяет современные тенденции заболеваемости и смертности населения региона.

Ключевые слова: эпидемический переход; инфекционные заболевания; смертность; заболеваемость; экзогенные факторы; эндогенные факторы; квазиэкзогенные факторы; городское население; Среднее Поволжье; развитие медицины; советская медицина; успехи медицинской науки; сердечно-сосудистые заболевания; демографический переход; заболеваемость новообразованиями; развитие медицины в России.
\end{abstract}

«Эпидемический переход» - важный этап в эволюции демографического развития человечества. Факторы, его составляющие, по-прежнему являются актуальнейшей проблемой демографической истории. В данной работе нами будет рассмотрен такой немаловажный фактор «эпидемического перехода», как развитие медицины. Под «эпидемическим переходом» мы понимаем изменения в структуре заболеваемости и смертности населения, произошедшие в результате резкого снижения смертности от экзогенных факторов (эпидемии и голод), и относительного роста смертности от эндогенных факторов (заболеваний кровеносной системы, злокачественных новообразований).

Может показаться, что об успехах советской медицины уже многое сказано (взять хотя бы выходившие регулярно работы по истории советского здравоохранения) [1-3], но работ, связывающих 
Румянцева М.А.

Развитие медицины как фактор «эпидемического перехода» у городского населения...

«эпидемический переход» и достижения медицины первой половины XX века, не так много (например, это работы Е.М. Андреева, Л.Е. Дарского, Т.Л. Харьковой, В.Б. Жиромской, В.А. Исупова, В.Г. Семеновой и др.) [4-11], и совсем нет их применительно к Среднему Поволжью.

Развитие медицины будет рассматриваться нами как многофакторный процесс. Это рост числа врачей, среднего медицинского персонала и числа больничных коек. Это и появление новых методов лечения, диагностики и предотвращения инфекционной заболеваемости. Часть этих достижений, безусловно, принадлежит советской власти, другая же является результатом развития медицины как науки и носит общемировой характер.

Начать следует с изменения системы здравоохранения в СССР. Советская медицина становится бесплатной, что резко повышает ее доступность для всех слоев населения вне зависимости от их достатка. Растет число врачей. В 1966 году только в Куйбышевской область начитывалось более 7 тысяч врачей, тогда как на начало 1914 года во всей России их число не достигало и 16 тысяч [12, с. 404-421]. Численность врачей в РСФСР в 1966 по сравнению с 1941 годом абсолютном выражении выросла в 3,5 раза, рассматриваемом нами регионе в 4,2 раза, а в наиболее развитой в промышленном отношении Куйбышевской области в 5,4 раза. При этом численность врачей на 10 тыс. чел. населения в РСФСР выросла в указанный период в 3 раза, а в Ульяновской области в 5 раз, в Пензенской в 3,8 раза, в Куйбышевской в 3,5 раза, в Татарской АССР (ТАССР) в 3,2 раза. В числовом выражении лидером снова оказывается Куйбышевская область: 28,5 врачей на 10 тыс. чел. населения в 1966 году против 8,1 на 10 тыс. чел. населения в 1941 году. Число больничных коек выросло в среднем в 3 раза, а в Куйбышевской области опять зафиксирован рекордный показатель - в 3,8 раза. В 2-2,5 раза выросло и количество фельдшерских, акушерских и других медицинских пунктов в регионе, при этом лидером и в абсолютном, и в относительном выражении оказалась Татарская АССР. А вот рост количества женских консультаций, детских поликлиник и амбулаторий не столь равномерен. Впечатляющий рост числа женских консультаций, детских поликлиник и амбулаторий в Пензенской и Куйбышевской областях намного превышает аналогичный показатель в ТАССР и РСФСР. Однако абсолютные цифры дают несколько иную картину. Больше всего женских консультаций, детских поликлиник и амбулаторий как раз в ТАССР, затем следует Куйбышевская область и только потом Пензенская, в конце же списка оказалась Ульяновская область. И все же, несмотря на указанные противоречия, мы наблюдаем уверенный рост как числа врачей, так и числа медицинских учреждений и больничных коек во всех рассматриваемых регионах (табл. 1).

Однако только доступность медицинского обслуживания не смогла бы столь кардинально поменять структуру заболеваемости и смертности. В 1940 году в РСФСР смертность населения составляла 20,6\%, а в 1960 уже 7,4\%о, младенческая же смертность упала с 205,2\%о до 36,6\%о [12, с. 404-421]. Другим важнейшим фактором, повлиявшим на эпидемический переход, явились успехи медицинской науки - как российской и советской, так и мировой.

В начале XX века открыли возбудителей многих инфекционных заболеваний (например: чумы, туберкулеза, малярии, гнойных инфекций и т.д.) [13; 14 , c. $77-229 ; 15$, с. $367 ; 16$, с. 285-304]. Но прошли годы, прежде чем эти открытия повлияли на заболеваемость и смертность населения. Даже сейчас это не происходит быстро. В качестве примера мы сможем привести возбудителя язвы желудка и двенадцатиперстной кишки Helicobacter pylori. Открыли его еще в 1980-х годах, но массово лечить антибиотиками стали только после 2000 года [13].

Таблица 1 - Развитие системы здравоохранения в Среднем Поволжье в 1940-1960-х гг.

\begin{tabular}{|c|c|c|c|c|c|c|}
\hline Годы & РСФСР & $\begin{array}{c}\text { Куйбышевская } \\
\text { область }\end{array}$ & $\begin{array}{c}\text { Пензенская } \\
\text { область }\end{array}$ & $\begin{array}{c}\text { Ульяновская } \\
\text { область }\end{array}$ & $\begin{array}{c}\text { Татарская } \\
\text { АССР }\end{array}$ & $\begin{array}{l}\text { Среднее } \\
\text { Поволжье }\end{array}$ \\
\hline \multicolumn{7}{|c|}{ Численность врачей, чел. } \\
\hline 1941 & 90842 & 1355 & 567 & 338 & 1806 & 4066 \\
\hline 1966 & 315538 & 7303 & 2095 & 1696 & 6068 & 17162 \\
\hline $1941 \kappa 1966$, раз & 3,5 & 5,4 & 3,6 & 5 & 3,4 & 4,2 \\
\hline \multicolumn{7}{|c|}{ Численность врачей на 10 тыс. чел. населения, чел. } \\
\hline 1940 & 8,2 & 8,1 & 3,5 & 2,9 & 6,2 & 5,1 \\
\hline 1965 & 24,8 & 28,5 & 13,4 & 14,4 & 19,7 & 19 \\
\hline $1941 \kappa 1966$, раз & 3 & 3,5 & 3,8 & 5 & 3,2 & 3,7 \\
\hline \multicolumn{7}{|c|}{ Число больничных коек, тыс. шт. } \\
\hline 1941 & 482,0 & 6,3 & 4,6 & 3,1 & 10,5 & 24,5 \\
\hline 1966 & 1241,1 & 24,2 & 11,6 & 9,9 & 26,8 & 72,5 \\
\hline $1941 \kappa 1966$, раз & 2,6 & 3,8 & 2,5 & 3,1 & 2,6 & 3 \\
\hline \multicolumn{7}{|c|}{ Число фельдшерских, акушерских и других пунктов } \\
\hline 1941 & 25127 & 408 & 351 & 338 & 726 & 1823 \\
\hline 1966 & 51849 & 832 & 805 & 625 & 1820 & 4082 \\
\hline $1941 \kappa 1966$, раз & 2,1 & 2,0 & 2,3 & 1,8 & 2,5 & 2,2 \\
\hline \multicolumn{7}{|c|}{ Число женских консультаций, детских поликлиник и амбулаторий, шт. } \\
\hline 1941 & 4917 & 62 & 37 & 36 & 130 & 265 \\
\hline 1966 & 10956 & 236 & 152 & 102 & 237 & 727 \\
\hline $1941 \kappa 1966$, раз & 2,2 & 3,8 & 4,1 & 2,8 & 1,8 & 2,7 \\
\hline
\end{tabular}

Примечание. Таблица рассчитана автором по: Народное хозяйство РСФСР за 70 лет [12, с. 404-421]. 
Развитие медицины в борьбе с инфекциями шло двумя путями: профилактическим и лечебным. К профилактике можно отнести массовое вакцинирование населения и меры по борьбе с переносчиками болезней - карантинные мероприятия, а также систему СЭС, охватившую всю страну. Прорыв в лечении связан, в первую очередь, с открытиями специфических и неспецифических противомикробных препаратов.

Самым известным открытием стало открытие Александром Флемингом в 1928 году пенициллина. Однако до начала Второй мировой войны не удавалось получить достаточно чистый пенициллин для опытов не только на клеточных культурах. Выделением занимались Эрнст Борис Чейн и Говард Флори в Оксфорде и 3.В. Ермолаева в СССР. С 1944 года пенициллин массово применяется в советской армии, сначала для лечения раневых инфекций, а позднее и для лечения сифилиса и респираторных инфекций. Значительно менее известно, что еще до войны Г. Домагк открыл пронтозил (1934 г.), сульфаниламидный препарат, также известный как стрептоцид, который позволял бороться с инфекциями, вызываемыми стрептококками, пневмококками, кишечной палочкой и возбудителем газовой гангрены. А в 1946 году было сделано другое эпохальное открытие: 3. Ваксман открыл стрептомицин, позволявший бороться с туберкулезом и чумой $[13 ; 14$, с. $77-229$; 15 , с. $367 ; 16$, с. $285-304]$.

Существенную роль в борьбе с острозаразными заболеваниями играет вакцинирование населения. В 1896 году появляется вакцина от холеры и чумы, в 1920-х годах от дифтерии, коклюша и столбняка, в 1930-х от гриппа, клещевого энцефалита и сыпного тифа, в 1950-х годах от бруцеллеза и полиомиелита, в 1960 -х от кори, паротита и краснухи $[13 ; 14$, с. $77-$ $229 ; 15$, с. $367 ; 16$, с. 285-304]. Именно массовое использование вакцин позволило существенно снизить заболеваемость и смертность от этих заболеваний. Так, использование АКДС (коклюш, дифтерия, столбняк) привело к резкому снижению заболеваемости у детей. За десять лет дифтерия стала встречаться в Поволжье в 47 раз реже, коклюш в 3,5 раза, бруцеллёз в 1,8 раза реже [17, с. $161-162 ; 18$, с. $67-71]$.

В 1954 году А. Сейбин создал живую вакцину против полиомиелита. Массовое прививание населения этой вакциной привело к уменьшению заболеваемости полиомиелитом в 50 раз в РСФСР только за хрущевское десятилетие. В Среднем Поволжье в указанные годы это опасное заболевание стало встречаться на $43,3 \%$ реже, теперь случаи заражения полиомиелитом стали единичны [17, с. 161-162; 18 , c. $67-71]$.

Еще одним немаловажным фактором стало то, что здравоохранение в СССР носило государственный характер. Это позволило не только проводить массовые вакцинации населения, но и поставить выявление и профилактику инфекционных заболеваний в стране на качественно новый уровень. Для этого еще в 1930-х годах была создана сеть санитарноэпидемических станций (СЭС). Задачей СЭС стало проведение противоэпидемических и санитарно-профилактических мероприятий, «направленных на предупреждение загрязнения окружающей среды (водоемов, почвы, атмосферного воздуха), на оздоровле- ние условий труда, обучения, быта и отдыха населения, а также на контроль за организацией и проведением мероприятий по предупреждению и снижению инфекционной и профессиональной заболеваемости» [13]. На них же возлагалась пропаганда среди населения медицинских и гигиенических знаний. Так, повсеместная обработка водоемов и прибрежных областей от комаров и их личинок способствовала снижению заболеваемости впервые выявленной малярией в РСФСР в 8,5 раз, а в Поволжье в 63 раза за период с 1957 по 1964 года [17, с. 161-162; 18, с. 67-71].

Советская медицина может также гордиться высококачественной системой карантинных противоэпидемических мероприятий, что позволило не допускать крупных эпидемий острозаразных заболеваний в стране. При введении карантинных мероприятий в СССР прекращалось движение транспорта, населения и грузов за пределы карантинной зоны, при необходимости устанавливалась военная охрана. Активно выявлялись и изолировались больные, проводился комплекс лабораторных исследований, дезинфекция и дезинсекция зоны карантина. Снимался карантин только после того, как истекал максимальный срок инкубационного периода заболевания со времени выявления последнего больного [19]. Это все же не означает, что вспышки чумы, холеры или сибирской язвы не поражали население Страны Советов [20], но они перестали уносить сотни тысяч человеческих жизней [21, с. 214-344].

Как следствие, в 1950-1960-е годы структура смертности в регионе существенно меняется. Смертность от инфекционных заболеваний в Среднем Поволжье к концу рассматриваемого периода составляла менее $2 \%$ от всех видов смертей, тогда как злокачественные новообразования становились причиной каждой пятой смерти в регионе. Столь же высок был уровень смертности от болезней органов кровообращения и от болезней сердца, тогда как смертность от болезней новорожденных (ранее уносившая большое число детских жизней) составила менее $2 \%$. За означенный период вдвое упала смертность от таких заболеваний, как болезни легких и другие болезни органов дыхания, туберкулез [17, с. 161-162; 18, с. 6771]. Всё это говорит о том, что в Среднем Поволжье в 1950-1960-е годы быстрыми темпами идет процесс «эпидемического перехода».

\section{Список литературы:}

1. 50 лет советского здравоохранения. М.: Медицина, $1967.697 \mathrm{c}$.

2. 60 лет советского здравоохранения. М.: Медицина, 1977. $416 \mathrm{c}$.

3. 70 лет советского здравоохранения. М.: Медицина, $1987.512 \mathrm{c}$.

4. Вишневский А.Г. Воспроизводство населения и общество: история, взгляд в будущее. М.: Финансы и статистика, 1982. $287 \mathrm{c}$.

5. Вишневский А.Г. Демографическая революция. М.: Статистика, 1976. 240 с.

6. Брачность, рождаемость, смертность в России и в СССР / под ред. А.Г. Вишневского. М.: Статистика, 1977. 246 с.

7. Андреев В.М. Продолжительность жизни и причины смерти в СССР // Демографические процессы в СССР. М.: Наука, 1990. С. 90-92. 
8. Андреев Е.М., Дарский Л.Е., Харькова Т.Л. Демографическая история России: 1927-1957. М.: Информатика, 1998. 197 с.

9. Жиромская В.Б. Основные тенденции демографического развития России в XX веке. М.: Кучково поле, 2012. 320 с.

10. Исупов В.А. Эпидемический переход в России: взгляд историка // Демографическое обозрение. 2016. Т. 3, № 4. С. 82-92.

11. Семенова В.Г. Обратный эпидемиологический переход в России. М.: ЦСП, 2005. 235 с.

12. Народное хозяйство РСФСР за 70 лет: Статистический ежегодник. М.: Финансы и статистика, 1987. $471 \mathrm{c}$.

13. Большая медицинская энциклопедия / под ред. Б.В. Петровского, 3-е издание в 30-ти томах, М.: «Советская энциклопедия», 1974-1989 гг.

14. Носов С.Д. Детские инфекционные болезни. М.: Медицина, 1973. 535 с.

15. Шувалова Е.П. Инфекционные болезни. М.: Медицина, 1990. 560 с.
16. Заблудовский П.Е., Крючок Г.Р., Кузьмин М.К., Левит М.М. История медицины. М.: Медицина, 1981. $352 \mathrm{c}$.

17. Репинецкий А.И., Румянцева М.А. Городское население Среднего Поволжья в послевоенное двадцатилетие. 1945-1965 гг.: Очерки демографической истории. Самара: Изд-во «НТЦ», 2005. 262 с.

18. Румянцева М.А. Городское население Среднего Поволжья в 1956-1965 гг. Материалы к изучению демографической истории: сборник материалов и документов. Самара: СамГТУ, 2012. 176 с.

19. Инструктивно-методические указания по диагностике, лечению и профилактике чумы: инструкция Минздрава СССР // Сб. норм. док. по сан.-противоэпидем.режиму. Т. II .М.: Агар, 1996.

20. Бадугинова М.В. Борьба со вспышкой эпидемии чумы в Калмыцкой АССР и Сталинградской области в 1937-1938 гг. // Вестник Калмыцкого ин-та гуманитарных исследований РАН. 2012. № 2. С. 108-113.

21. Васильев К.Г., Сегал А.Е. История эпидемий в России. М.: Медгиз, 1960. 398 с.

\title{
THE DEVELOPMENT OF MEDICINE AS A FACTOR OF «EPIDEMIC TRANSITION» IN THE URBAN POPULATION OF THE MIDDLE VOLGA REGION
}

\author{
Rumyantseva Maria Aleksandrovna, candidate of historical sciences, associate professor, \\ researcher of Economics and Management Department \\ Branch of Samara State Technical University in Novokuibyshevsk \\ (Novokuibyshevsk, Samara Region, Russian Federation)
}

Abstract. In the paper the author considers the development of medicine in the twentieth century as a factor that significantly changed the morbidity and mortality of the population of the Middle Volga region. The emergence of penicillin and streptomycin, mass vaccination campaigns and promotion of healthy work and life, vector control and advances in medical science, an increase in the number of doctors and hospital beds per capita and affordable free medical care led to a significant reduction in the number of dangerous epidemics in the country. The urban population of the Middle Volga region faced these processes, too. Cases of polio and malaria, anthrax and tularemia, plague and diphtheria, smallpox and cholera were reduced to a few ones, cases of typhus and dysentery decreased significantly, which inevitably led to a shift in the structure of mortality in the region, exogenous mortality factors gave way to endogenous ones. The shift of morbidity towards neoplasm's and cardiovascular diseases was also a trend of the time. And it was the process of «epidemic transition» that occurred in the second half of the last century, as part of the demographic transition, that determined the current trends in morbidity and mortality of the region's population.

Keywords: epidemic transition; infectious diseases; mortality; morbidity; exogenous factors; endogenous factors; quasi-exogenous factors; urban population; Middle Volga region; development of medicine; Soviet medicine; successes of medical science; cardiovascular diseases; demographic transition; morbidity of neoplasms; development of medicine in Russia.

$* * *$

УДК 371 (09)

DOI 10.24411/2309-4370-2020-11214

Статья поступила в редакцию 24.01.2020

\section{РЕФОРМИРОВАНИЕ СИСТЕМЫ ШКОЛЬНОГО ОБРАЗОВАНИЯ В 1958-1964 ГГ.: ЗАДАЧИ И ПРОСЧЁТЫ}

(C) 2020

Репинецкий Александр Иванович, доктор исторических наук, профессор, проректор по научно-исследовательской работе, профессор кафедры отечественной истории и археологии Самарский государственный сочиально-педагогический университет (2. Самара, Российская Федераџия)

Рябов Виктор Васильевич, доктор исторических наук,

профессор, член-корреспондент Российской академии образования,

президент университета, заведующий кафедрой всеобщей и российской истории

Московский городской педагогический университет (г. Москва, Российская Федерация)

Аннотация. Реформирование, проходившее в СССР во второй половине 1950-х - начале 1960-х гг., затронуло и систему образования. В статье рассмотрены причины проведения реформы школьного образования в 